\title{
Os teatros públicos na capital das Minas setecentistas: da casa da Ópera de Vila Rica ao Theatro do Ouro Preto
}

\author{
Rosana Marreco Brescia ${ }^{1}$
}

\section{Resumo}

Foi durante o reinado de D. José I que a atividade operística se estabeleceu de forma definitiva em solo luso-americano, quando diversos teatros permanentes foram construídos de norte a sul do vasto território português na América, na maioria dos casos, seguindo os parâmetros construtivos e administrativos já utilizados nos teatros da metrópole. Dentre os teatros construídos na América Portuguesa no século XVIII, destaca-se a Casa da Ópera de Vila Rica/Ouro Preto, sobretudo por ser o único exemplar que segue a tipologia dos teatros públicos portugueses setecentistas remanescente no mundo luso-brasileiro. Este artigo pretende traçar as origens da Casa da Ópera de Ouro Preto, esclarecendo alguns pontos em relação à administração do estabelecimento nos séculos XVIII e XIX, à arquitetura do edifício setecentista e às inovações introduzidas na década de sessenta do século XIX.

\section{Palavras-chaves}

Ópera, teatro, João de Sousa Lisboa, arquitetura teatral.

I Doutoranda da Université Sorbonne - Paris IV, Centro de Estudos em Sociologia e Estética Musical - Universidade Nova de Lisboa. E-mail: romarreco@yahoo.com.br 


\title{
Public Theatres in the Capital of Minas Gerais in the 18th century: from the Opera House of Vila Rica to the Theatre of the Ouro Preto
}

\author{
Rosana Marreco Brescia
}

\begin{abstract}
It was during the reign of Joseph I (1750-1777) that operatic activity was established in Luso-American colonies; several permanent theatres were built across Portugal's vast territories in America, most of them following the architectural and administrative models already in use at the public theatres of Portugal. The Opera House of Vila Rica/Ouro Preto stands out amongst these Portuguese American theatres of the 18th century as the sole surviving example of Portuguese public theatre typology. This paper intends to outline the origins of Ouro Preto's Opera House, considering issues of its organisation and administration in the course of its existence, the architecture of its 18th century building, and the innovations introduced to the structure during its mid-19th century restoration.
\end{abstract}

\section{Keywords}

Opera, theatre, João de Sousa Lisboa, theatrical architecture. 


$$
O
$$


em atividade na capitania de Minas Gerais, o artigo de Celso Falabela de Castro $^{4}$, que merece destaque por ter publicado pela primeira vez o parecer da comissão fiscal, formada após as obras de adaptação do edifício em 1861/1862, documento fundamental para a compreensão das características originais do teatro e as inovações advindas das mencionadas obras, e o livro de Rogério Budasz ${ }^{5}$, sem dúvida alguma a melhor e mais completa publicação sobre os teatros históricos luso-americanos até o momento. No panorama teatral das vilas e cidades coloniais, Vila Rica destaca-se como uma das três cidades da América Portuguesa que contavam com um teatro permanente ainda durante o reinado de D. João $\mathrm{V}$, juntamente com o Rio de Janeiro, cujo teatro fora construído em $1719^{6}$, e Salvador, na Bahia, onde um teatro de funcionamento permanente fora armado na Câmara da então capital do Brasil em 17297.

A primeira Casa da Ópera construída na capital da Capitania das Minas Gerais, ainda na primeira metade do século XVIII, não teria resistido às intervenções feitas por João Martins na ocasião das celebrações pela aclamação de D. José ao trono português, comemoradas em Vila Rica em $1751^{8}$, quando teria sido ajustada com a Câmara a demolição da parede frontal da Casa da Ópera, para que mais espectadores pudessem assistir às três óperas realizadas na efeméride - O labirinto de Creta, $O$ velho Serjo e Os encantos de Merlin $^{9}$-, arrematadas por Francisco Mexias ${ }^{10}$. No dia 5 de maio do mesmo ano, um documento de acerto de contas entre o Senado da Câmara e Manoel Ferreira do Carmo, informa que várias paredes de dentro da Casa da Ópera ruíram devido ao grande número de espectadores que assistiram aos espetáculos ${ }^{11}$. Na verdade, não nos surpreende que a estrutura do teatro fosse completamente abalada ao retirar-se uma das paredes do edifício, já que, segundo o sistema

4. CASTRO, Celso Falabela de. Teatro de Ouro Preto, o mais antigo da América do Sul. Revista de Historia e Arte, 1963. p.75 - 77.

5 BUDASZ, Rogério. Teatro e música na América Portuguesa: ópera e teatro musical no Brasil (1700-1822). Curitiba: Deartes Universidade Federal do Paraná, 2008.

6 ANRJ, Livro 28, 2º Oficio de Notas do Rio de Janeiro, 1719. p. 186-187.

7 AHU_ACL_CU_005, Cx.45, d. 4043, Rolo 50.

8 APM, CMOP - Cx.25, d.11, fl.o3

9 A ópera $O$ labirinto de Creta é de autoria de Antônio José da Silva. A obra Os encantos de Merlin foi representada em Lisboa no Teatro da Mouraria, em 1741, e publicada no quarto volume do Theatro cómico portuguez. O velho Serjo trata-se, muito provavelmente, do libreto Discrição, harmonia e formosura, conservado em manuscrito nas obras reservadas da Biblioteca Nacional de Lisboa e recuperado pelo musicólogo Rogério Budasz.

10 APM, CMOP - Cx.25, d.11, fl.oz.

11 APM, CMOP - Cx.25, d.og, fl.o1v. 
construtivo empregado na época, todas as paredes eram estruturais, constituindo assim, uma parte vital do edifício.

Ao que tudo indica, Vila Rica teve que esperar dezoito anos até que outra Casa da Ópera permanente fosse edificada. Foi somente em 1769 que João de Sousa Lisboa teve a iniciativa de construir um novo teatro em um de seus terrenos, situado à rua de Santa Quitéria, logo abaixo da Igreja da Venerável Ordem Terceira de Nossa Senhora do Carmo ${ }^{12}$. Os primeiros registros sobre João de Sousa Lisboa em Minas Gerais datam da década de quarenta do século XVIII e comprovam a grande fortuna acumulada com a arrematação de contratos de entradas e dízimos na Capitania; primeiro na comarca do Rio das Mortes ${ }^{13}$, e, após 1748, na Comarca de Vila Rica. Dentre os sucessos e contratempos na vida do contratador, destacamos sua promoção para o cargo de capitão da Ordenança de uma das Vilas de Pé de São João del Rei ${ }^{14}$, para o posto de coronel do Regimento da Nobreza dos Privilegiados e Reformados de Vila Rica, em 8 de Setembro de $1761^{15}$ e sua prisão em 1766, consequência de uma enorme dívida relativa aos contratos por ele arrematados na década de $1760^{16}$.

Segundo o próprio coronel Sousa Lisboa, a ideia de construir um novo teatro permanente em Vila Rica não teria sido sua. Em uma carta endereçada ao amigo João Batista Carvalho, em 31 de julho de 1770, Lisboa informa o seguinte: "Também dou a vossa mercê parte em como estou aqui / encarregado de hua Caza de Opra que me mandarão fazer, e a fis que / me chegou a dezaseis mil cruzados e agora não tenho mais remédio que su / prir com o que he precizo para ella para ver se posso salvar o dinheiro" ${ }^{17}$.

Embora seja certo de que todas as despesas relativas à construção e ao funcionamento do edifício da Casa da Ópera tenham ficado a cargo de João de Sousa Lisboa, um documento que expõe às autoridades da metrópole os problemas concernentes à administração dos negócios do coronel, após sua morte, nos indica que o antigo contratador não contava com um patrimônio tão extenso à altura da arrematação de seu primeiro contrato:

12 APM, CMOP - Cx.059, fl.324.

13 AHU_ACL_CU_o11, Cx.46, d.98, rolo 40.

14 AHU_ACL_CU_o11, Cx.48, d.23.

15 ANTT, Chancelaria de D. José I, Livro 70, fl.ı6ıv.

16 João de Sousa Lisboa foi liberado do cárcere alguns meses mais tarde por ordem do próprio rei de Portugal, como confirma o documento recuperado por nós no Arquivo Ultramarino de Lisboa (HU_ACL_CU_o11, Cx.88, d.46, Rolo 79).

17 APM, CC - 1206, fls. 2, 2v e 3 . 
E por-boas Conjecturas, vem a pertencer Liquido ao Coronel João / de Souza Lx.a, pelos seus interesses fora das Sociedades dos Con/ tractos : porem se bem se Refletir, tal se naõ deve prezumir, / nem acreditar, muito principalmente havendo quem afirme, que / o mesmo Coronel, quando Rematou o primeiro Contracto dos / Dizimos, naõ possuhiria, se naõ quinze mil cruzados, ou pouco / mais, e que gastaria desse tempo, tè o em que falleceo nos se- / us excessos, mais de Secenta, ou Setenta, naõ dizendo o muito q' / despendeu em duas vezes, que passou à Corte : logo nesse cazo, to- / do o chamado particular, he do Corpo dos Contractos. [...] // e outro que se deu a Juro pelo lucro do premio, perto de trinta / Mil cruzados, que se despenderaõ na factura, e fabrica da Caza / da Opera, tudo com Titulo de particular. Hè bem certo, / e a todas as luzes manifesto, que todo este dinheiro se tirou do / Milhor; e mais prompto que havia dos ditos Contractos, sem / Separaçaõ deste, ou daquelle : assim como, o que se pagou de cus- / tas, que todas sahiraõ do Monte Mor ; e tudo se despendeo, sem / se dizer a quem pertencia, pelo que se deve julgar, que nada ha- / particular, e que tudo o que aparece he dos Contractos, porem- / de quaes, Deos o Sabe. ${ }^{18}$

Independentemente da proveniência do capital investido na construção da Casa da Ópera, sabemos que, em 1769, o carpinteiro Mateus Garcia ajustou com o coronel Sousa Lisboa para deitar as telhas do novo teatro que se construía na Rua de Santa Quitéria pelo preço de dezenove oitavas de ouro por cada milheiro ${ }^{19}$ o que nos indica que a edificação do teatro já estava quase concluída.

Alguns meses mais tarde, João de Sousa Lisboa mencionava a contratação de Marcelino José de Mesquita para a realização das pinturas decorativas na Casa da Ópera a seu amigo Joaquim José Marreiros:

Recebo a de vossa mercê do primeiro de Março em que me dis que lhe esqueceo dizer-me / se achava nessa villa Marcellino Joze e que não he mau para a pintura da caza da / hopera, eu assim ouço dizer, mas este sogeito aqui veyo a esta Villa a seu negocio, / e se me fallou por parte delle para pintar a dita caza, no que não tive duvida, e orde / ney que me fallace, e com effeyto me veyo

18 APM, CC - Cx.75 - Planilha 20024 fl.1.

19 ANRJ, Coleção da Casa dos Contos de Ouro Preto, Rolo 614, Sub-lote o8, Cx. 290, Grupo o2. A documentação avulsa da Coleção da Casa dos Contos de Ouro Preto, preservada no Arquivo Nacional do Rio de Janeiro, encontra-se atualmente em processo de recatalogação. 
fallar, e me asseverou a que queria fazer / ainda que foçe de graça porque queria mostrar a sua sabedoria, ao que / lhe respondy, que de graça me não servião por não ter obrigação de o fazer / sim que queria pagar, e que a tomaçe a sua conta de impreitada, e vice o quanto / lhe havia de ser, e afinal vinde ajustar comigo me pedia hum desprepo / zito de sorte que nenhum negocio fis com elle, e como vossa mercê me dis que se eu / quizer que elle venha que virá, se vossa mercê fallar com elle lhe dirá que quero / entrar com a pintura porque 6 de Junho hey de dar a caza corrente, que faz / annos Sua Magestade, e que se elle ouver de vir ha de estar aqui te 15, ou 16 deste há de estar / aqui, que te então não dou a obra, e passado esse tempo a dou. ${ }^{20}$

De fato, Marcelino José de Mesquita voltou a Vila Rica, e tudo indica que ele tenha realizado as pinturas decorativas no teatro da então capital. Anos mais tarde, o viajante francês Auguste de Saint-Hilaire, que teve a oportunidade de assistir a um espetáculo na Casa da Ópera em questão, descreve da seguinte forma a decoração do teatro: "O pano de boca representa as quatro partes do mundo pintadas da maneira mais grosseira, mas, dentre as decorações, que são muito variadas, existem algumas passáveis"21. É notável que as pinturas decorativas da Casa de Fundição de Sabará ${ }^{22}$, atual Museu do Ouro, que conserva, em uma de suas salas, um forro decorado com o mesmo motivo das quatro partes do mundo (fig. 1), sejam igualmente de autoria de Marcelino José de Mesquita.

A temática histórico-mitológica não é frequente nas pinturas realizadas em Minas Gerais no século XVIII, e, portanto, nos parece que o motivo representado no pano de boca da Casa da Ópera de Vila Rica, provavelmente sugerido pelo proprietário do estabelecimento, como era habitual no caso das decorações dos teatros setecentistas, teria inspirado Mesquita na decoração da bela casa sabarense. Ao contrário do que afirma Rogério Budasz ${ }^{23}$, cremos que o pano de boca, descrito por Auguste de Saint-Hilaire, se tratasse do mesmo pintado por Marcelino José de Mesquita na inauguração do teatro de Vila Rica.

Marcelino teria sido também um dos primeiros empresários da Casa da Ópera, para quem João de Sousa Lisboa teria arrendado o teatro

20 APM, CC - 1205, fls. $11 v$ e 12.

21 SAINT-HILAIRE Auguste. Voyage dans les provinces de Rio de Janeiro et Minas Gerais. Paris: Grimbert et Dorez, 18zo, v. 1, p. 148.

22 APM, SC - Códice 230, fls.14-14V.

23 BUDASZ Rogério. op.cit., p. 47 
por um período de dois anos, pelo valor de 300 mil réis anuais, devendo ser pagos em barras de ouro, em três parcelas de $100 \mathrm{mil}$ réis a cada quatro meses ${ }^{24}$. No contrato, Sousa Lisboa deixa claro que deve ficar reservado para seu uso pessoal o camarote de número 14 do primeiro andar do lado esquerdo, e que o arrendatário não teria nenhum direito de emprestar, vender ou alterar os figurinos, solfas e bastidores existentes na Casa da Ópera, sob a pena de 50 mil réis de multa, pois esses elementos, bem como todos os novos que fossem fabricados para as novas óperas no período do contrato, eram de propriedade do teatro ${ }^{25}$.

$\mathrm{O}$ contrato de arrendamento em muito se assemelha àquele celebrado entre o Padre Boaventura Dias Lopes e Salvador Carsino de Brito, relativo ao arrendamento da Ópera dos Vivos no Rio de Janeiro em $1754^{26}$, nos quais vemos que o empresário não se tornaria proprietário de nenhum material utilizado nas óperas, mesmo que esses tivessem sido fabricados durante sua administração.

Mesquita estaria desobrigado de pagar o arrendamento caso o teatro fosse fechado por motivo de lutos reais ou por ordens do Governador da Capitania e dos ministros. Tal isenção também compreendia os períodos em que o teatro não pudesse funcionar por causa de incêndio ou "demolição das paredes", nesse caso, o proprietário seria o responsável pelos consertos e pelas obras que fossem necessárias, e não o arrendatário ${ }^{27}$.

A partir de um estudo exaustivo sobre o estabelecimento e a atividade das Casas da Ópera da América Portuguesa no século XVIII, concluímos que a grande maioria dos teatros permanentes da colônia foi construída por homens naturais da metrópole, tanto civis como eclesiásticos. A documentação até o momento encontrada nos indica que depois de concluídas, as Casas da Ópera eram arrendadas a empresários que ficariam responsáveis por todos os detalhes relativos às produções, contudo, todo o rendimento proveniente da venda de bilhetes e assinaturas de camarotes, após o pagamento do arrendamento anual da Casa da Ópera a seu proprietário e os salários de todos os profissionais envolvidos nos espetáculos, seria destinado ao empresário ${ }^{28}$.

24. Ao que tudo indica, o primeiro empresário da Casa da Ópera teria sido Luís de Barros, administrador do teatro de junho de $177^{\circ}$ a agosto de 1771 (APM, CC - Cx. 124, planilha 20.938/5). Marcelino José de Mesquita arrendou o estabelecimento a partir de setembro de 1771 .

25 AHMI, 1o Oficio de Notas, v. 151, fl. 107v.

26 ANRJ, $2^{\circ}$ Oficio de Notas da Cidade do Rio de Janeiro, Livro de Escrituras $\mathrm{n}^{\circ} 7^{\circ}$, fls. $27-27 \mathrm{~V}$.

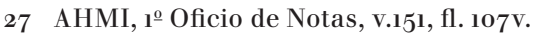

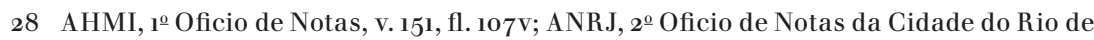
Janeiro, Livro de Escrituras $\mathrm{n}^{-0}$ 7o, fls 27-27v. 
Mesmo não fazendo parte de suas obrigações como proprietário do teatro, já que a produção era de responsabilidade do empresário, Sousa Lisboa se esforçou em prover seu estabelecimento de tudo o que fosse preciso para as representações, chegando a anunciar seus êxitos aos amigos que não se encontravam em Vila Rica, além de pedir-lhes auxílio para a contratação de atores e compra de materiais para a Casa da Ópera ${ }^{29}$.

Após ter conseguido contratar os atores necessários para as representações, Sousa Lisboa escreveu orgulhoso ao amigo Joaquim José Freire de Andrade, a 20 de setembro de 1770, informando-lhe que: "Saberá vossa mercê que já tenho na Caza da Opera du / as fêmeas que reprezentão e hua delas com todo o primor muito melhor que as / do Rio de Janeiro, e estimarei que vossa mercê tenha também por lá

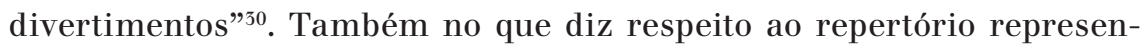
tado, João de Sousa Lisboa empenhou-se ao máximo para conseguir folhetos de obras teatrais e dotá-los de solfas musicais para que as mesmas pudessem ser representadas em Vila Rica ${ }^{31}$.

Após um sistemático levantamento dos títulos das obras representadas na América Portuguesa ao longo do século XVIII e de informações sobre a prática das Casas da Ópera luso-americanas no mesmo período, concluímos que o repertório apresentado na Casa da Ópera de Vila Rica, bem como aquele representado nos teatros públicos de Lisboa, era composto, sobretudo, de obras adaptadas "ao gosto português". Isto é, obras traduzidas do teatro italiano, francês e espanhol para o português, processo que muito frequentemente contava com a inclusão de personagens cômicos, conhecidos como "graciosos", à trama. A análise dos dois únicos folhetos teatrais encontrados até o presente estudo, ambos muito provavelmente utilizados por companhias dramáticas estabelecidas em Minas Gerais, comprova que o texto teatral era declamado, intercalando-se as falas com árias, duetos e coros cantados. Esses trechos musicados poderiam ser de autoria de compositores locais ou extraídos de óperas italianas e cantados em italiano ${ }^{32}$.

Ainda nos primeiros anos de funcionamento da Casa da Ópera, encontramos entre os assinantes dos camarotes nomes como o de João Rodrigues de Macedo ${ }^{33}$, rico contratador e proprietário do imóvel na

29 APM, CC - 1205, fls.27v-28.

30 APM, CC - 1174, fls.4, v, 4,2 e 4,2v.

31 APM, CC - 1205, fls.45v-46.

32 TUCKEY James Kingston. An account of a voyage to establish a colony at Port Philipe in Bass's Strait, on the south coast of New South Wales in His Majesty's ship "Calcutta" in the years I802-3-4. London: Longman, Hurst, Rees, and Orme, 1805. p. 52-53. ACL/UFMG - 9.1.09.15. 
atualidade conhecido como "Casa dos Contos"; do capitão mor José Álvares Maciel, pai do inconfidente homônimo; do Intendente do Ouro José João Teixeira Coelho; do desembargador João Caetano dos Santos; além do próprio Cláudio Manoel da Costa, que teria traduzido para o português obras de Pietro Metastasio para serem representadas no Teatro da então capital mineira ${ }^{34}$. Dentre os assinantes, alguns estavam diretamente relacionados ao movimento da Inconfidência Mineira ${ }^{55}$, fato absolutamente compreensível se considerarmos que o teatro era o único espaço público de convivência profana disponível em Vila Rica no século XVIII, como nos confirma Saint-Hilaire:

Se os habitantes de Vila Rica possuem em sua cidade um só estabelecimento de caridade, e se eles fazem poucos sacrifícios para sustentá-lo, ao menos não se pode condená-los por gastar com os prazeres, ao menos por aqueles que lhes são permitidos. Não se encontra na cidade nenhum passeio público, nenhum café razoável, nenhuma biblioteca, nenhum cabinet literário, nenhum lugar de reunião, e os estrangeiros não tem nem mesmo condições de encontrar um albergue passável. Na verdade, existe uma sala de espetáculos em Vila Rica, mas, como nos veremos adiante, ela supre muito pouco tantas outras privações. ${ }^{36}$

João de Sousa Lisboa faleceu em 1778, deixando uma dívida de 388 \$413.782 réis para com o Erário Régio, segundo cópia de uma carta da rainha Dona Maria I, recuperada no Arquivo Ultramarino de Lisboa. De acordo com o procedimento comum naquele tempo, fez-se a penhora dos bens pela Fazenda Real; todo o patrimônio fora inventariado, separando as contas que ele tinha com sócios de diversos contratos, e os bens foram colocados em praça pública para que pudessem ser arrematados ${ }^{37}$.

Além da viúva, que o coronel deixara em Vila Rica, Sousa Lisboa tinha dois sobrinhos residentes em Lisboa de nomes Pedro e Eusébio, que decidiram transferir-se para Minas Gerais em busca do tio. Quando aportaram no Rio de Janeiro, tomaram conhecimento do falecimento de Sousa Lisboa e fizeram requisição à Junta da Real Fazenda do direito de

34 APM, Col. APM Cx.o1, d.oz.

35 ANRJ, Coleção da Casa dos Contos de Ouro Preto Rolo 614, Sub-lote o8, Cx.29o, Grupo 02.

36 SAINT-HILAIRE Auguste. op.cit., v.1, p. 147-148.

37 AHU_ACL_CU_o11, Cx. 114, d.51, Rolo 102. 
administrar os bens do falecido ${ }^{38}$. Tal direito foi concedido pela soberana portuguesa por meio de uma real ordem datada de $1779^{39}$.

No que diz respeito à Casa da Ópera, tudo indica que o teatro teria continuado a ser arrendado a empresários particulares, que pagavam o valor do arrendamento à Real Fazenda, como podemos comprovar em um processo envolvendo António de Pádua, empresário do teatro na última década do século XVIII. No referido processo, lemos "[...] Ser publico e notorio que / o Autor [Antonio de Padua] he morador nesta Villa e na / mesma Si ocupa no exzersisio de em / prensario da Caza da opera cuja Caza / adimenistra por arendamento que / paga a Rial Fazenda"40.

Alguns anos mais tarde, outro documento, datado de 19 de abril de 1820, e preservado no Arquivo Público Mineiro, indica que o teatro seria de responsabilidade do departamento das Obras Públicas de Vila Rica, contudo, era arrendado ao empresário José Joaquim Vieira Souto ${ }^{41}$.

Ainda não encontramos documentos correspondentes ao período que sucedeu à Independência do Brasil, o que nos impede de estabelecer uma ideia mais precisa de como teria sido feita a administração da Casa da Ópera. O que se sabe de concreto é que a 5 de setembro, de 1851, a Sociedade Dramática Ouropretana, na pessoa de seu presidente António Inocêncio de Azevedo Castro, juntamente com outros membros, requereu à Assembleia Legislativa Provincial de Minas Gerais uma "módica subvenção" para realizar obras de reparo na antiga Casa da Ópera da Capital da Província, que parecia estar "desde longos tempos [...] em deplorável estado de deterioração"42.

Levantamos grande quantidade de anúncios, publicados nos jornais mineiros, relativos a representações de natureza variada, realizadas na Casa da Ópera durante o período em questão, prova cabal de que, apesar do estado do edifício, o teatro estava em pleno funcionamento. Dentre os espetáculos realizados na década de cinquenta do século XIX, encontramos diversas obras encenadas pela companhia de José Caetano Viana, além de alguns recitais interpretados pela grande soprano milanesa Augusta Candiani $^{43}$. Contudo, apesar da presença ilustre de Candiani no palco do

38 AHU_ACL_CU_o11, Cx.111, d. 9o, Rolo 99 .

39 AHU_ACL_CU_o11, Cx. 114, d. 51, Rolo 102.

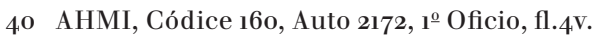

41 APM, CC - Cx. 134, planilha 21.140/4, fl.1.

42 APM, AL - 1/8, 1851/og/05, Pasta 42.

43 A soprano Milanesa Augusta Candiani chegou ao Rio de Janeiro em 1844, com a Companhia Dramática Italiana, e foi, durante vários anos, a prima-donna do Real Teatro São Pedro de Alcântara daquela cidade. Responsável pela criação de alguns dos papéis mais importantes do repertório do Bel Canto Italiano, Candiani tornou-se célebre no papel de Norma, na Ópera homônima de Vincenzo Bellini, tendo interpre- 
teatro da então capital, não foram encontrados registros de outras representações do gênero lírico, encenadas ou em forma de concerto.

O repertório mais frequentemente representado parece ser constituído de espetáculos de ginástica e prestidigitação, além de obras do teatro declamado, dentre as quais destacamos: o drama Luis de Camões, a farsa $O$ juiz de paz da roça, A sorte dos ladrões ou a Dama roubada, $A$ nova Castro, o Pobre mendigo, de Mme. Staël, O fronteiro de Africa, de Alexandre Herculano, O caixeiro da taberna, de Martins Penna, entre outras $^{44}$. É importante mencionar que o primeiro baile de carnaval realizado em Ouro Preto também teve lugar na sala da Casa da Ópera, como podemos verificar em um artigo publicado no Correio Oficial de Minas, em 9 de fevereiro de 1857:

Nos dias 22 e 24 do corrente terão lugar pela pri- / meira vez nesta cidade as festas denomimadas [sic] Carnaval, / que constará de grande passeio a cavallo á tarde de pes- / soas gradas vestidas a carácter, e substituindo por flô- / res o bárbaro jogo d’agua denominado Entrudo; á noite / terá lugar o baile no theatro d'esta cidade: annunciar-se- / há depois o programma. ${ }^{45}$

Apesar da intensa programação do teatro da então capital, e de seu frágil estado de conservação, tudo indica que até 1852 nenhuma iniciativa havia sido tomada em relação às obras de restauração do edifício ${ }^{46}$. Foi somente em 1854 que a Assembleia Legislativa Provincial, na pessoa de seu presidente Francisco Diogo Pereira de Vasconcelos, decidiu tomar uma atitude em relação às obras do teatro, e então, descobriu-se que a Casa da Ópera ainda era propriedade do falecido João de Sousa Lisboa, cujos bens foram sequestrados em 13 de abril do ano de seu falecimento, 1778, e, desde então, vinha sendo administrada pela tesouraria da Fazenda "que entretanto nenhum lucro tira, ou se o tira, é muito diminuto, de seu arrendamento"47.

tado a ária Casta diva em diversas ocasiões em várias cidades brasileiras, inclusive em Ouro Preto. APM, Jornais Mineiros do século XIX: O Bom Senso - 15/04/1856, Edição 399 - JM-1239467 e O Bom Senso - 15/05/1856, Edição 412 - JM-1239576.

44 APM, Jornais Mineiros do século XIX: $O$ Bom Senso - 12/05/1856, Edição 411 - JM1239575; O Bom Senso - 15/04/1856, Edição 399 - JM-1239467; O Bom Senso - 17/o9/1855, Edição 346 - JM-1239415; O Bom Senso - 06/o9/1855, Edição 344 - JM-1239413.

APM, Jornais Mineiros do século XIX, Correio Official de Minas - 09/02/1857, Edição 10 - JM-1262468.

46 APM, AL - 1/8, 1851/09/05, Pasta 42.

47 APM, Relatório da Assembleia Legislativa de Minas Gerais, 1854, p. 32-33 
Vasconcelos teria comunicado aos demais membros da Assembleia Legislativa o envio de um ofício ao Ministro da Fazenda no Rio de Janeiro, requerendo ou a alienação do Teatro ou a cessão do mesmo à Província de Minas Gerais. No caso de ser atendido, o presidente pretendia:

aproveitar este Edi- / ficio, dar-lhe uma nova forma interior, e convertel-o em um Theatro, que possa / offerecer os commodos precisos para darem-se regularmente algumas representações, / aproveitando-se d'est'arte talentosos já experimentados na declamação, e outros que / ahi surgem esperançosos. / Qualquer que seja a solução de S. Exc. o Sr. Ministro e Secretario d'Estado dos / Negocios da Fazenda ao meu pedido, nada embarga que autoriseis a Presidencia / com o credito necessario para as obras de que carece o Theatro, se convierdes / comigo nas observações que ficão expostas. ${ }^{48}$

O pedido de Francisco Diogo Pereira de Vasconcelos foi atendido, e, em 18 de maio de 1854, a lei no 686 creditava à Presidência da Província a quantia necessária para converter em propriedade Provincial o Teatro já existente na capital de Minas Gerais ${ }^{49}$. O artigo $2^{\circ}$ da mesma lei rezava que: "Se a despeza com a desapropriação e concerto for tal, que accrescentando-se um terço se possa construir um Novo Theatro, então o Governo mandara edificar" ${ }^{50}$.

A partir de então, o Dr. Júlio Borrel du Vernay, engenheiro da Província de Minas Gerais, foi contatado para examinar o edifício da antiga Casa da Ópera para fazer um parecer sobre o estado do teatro e as eventuais vantagens de se construir uma nova casa de espetáculos em Ouro Preto. Em 26 de janeiro de 1855, o engenheiro enviou o seu parecer à Assembleia Legislativa, no qual afirmava que as obras de conversão no antigo teatro custariam cerca de 32:866\$880 réis aos cofres públicos, enquanto a construção de um edifício inteiramente novo, mais amplo que o antigo, acarretaria um gasto de 33:924\$940 réis à Província ${ }^{51}$. Juntamente com o parecer, o engenheiro enviou um projeto contendo elevações das fachadas e plantas baixas do interior da sala de espetáculos para a consideração dos membros da Assembleia. Infelizmente, as plantas e elevações originais não foram encontradas até o presente

48 APM, Relatório da Assembleia Legislativa de Minas Gerais, 1854, p.32-33.

49 APM, Colecção de Leis da Assembleia Legislativa da Província de Minas Geraes, 1854. p. 47 .

50 APM, Coleção de Leis da Assembleia Legislativa, 1854. p.47

51 APM, AL - PPı/46, Cx.034, 1855/01/26, Pasta 07. 
estudo, mas preservam-se duas fotografias dos originais, conservadas na Biblioteca do Instituto do Patrimônio Histórico e Artístico Nacional, sediada em Belo Horizonte (fig. 2) ${ }^{52}$.

Segundo Borrel du Vernay, o novo teatro deveria localizar-se no mesmo terreno onde estava a Casa do Corpo Policial da capital, incorporando igualmente o terreno da casa vizinha. No projeto, vemos que o engenheiro da Província havia idealizado um teatro em estilo neoclássico, com dois pavimentos e um frontão triangular arrematando a fachada principal. A sala de espetáculos teria a forma de ferradura, e seria capaz de comportar cerca de seiscentos espectadores, divididos em três ordens de camarotes, plateia geral e plateia particular ${ }^{53}$.

Ao que tudo indica a Província não contava com a quantia necessária para a construção do novo teatro naquele ano, de modo que os planos foram postergados. A 1o de março de 1861, a Sociedade Dramática Ouropretana, praticamente dez anos após o primeiro pedido para que fosse tomada uma providência em relação ao antigo teatrinho, voltou a exigir que a lei, decretada em 1854, fosse cumprida. Segundo documento preservado no Arquivo Publico Mineiro, a reforma do antigo teatro ou a construção de um novo ainda não tinha acontecido devido ao estado de "penúria dos Cofres Provinciais" nos últimos anos ${ }^{54}$. No entanto, a partir de então as obras foram efetivadas, e, no dia 26 de março de 1861, o Presidente da Província encaminhou ao Inspetor da mesa de rendas provinciais, "a Planta do melhoramento interno do theatro d'esta cidade", confeccionada pelo então Engenheiro da Província Dr. Henrique Gerber, "natural do Reino de Hanover". A obra foi delegada ao carpinteiro Martinho Cesário de Sousa, no dia 27 de Março de $1861^{55}$.

É importante esclarecer que não foi construído um novo teatro no mesmo local onde sempre esteve a Casa da Ópera, edificada em 1770, mas, sim, foram executadas obras de restauração e de remodelação do antigo teatro, que sofreu uma mise au goût du jour, como tantos outros edifícios teatrais neste período. O Presidente Vicente Pires da Mota declarou na abertura da secção ordinária de 4 de agosto de 1861 que:

$5^{2}$ As fotografias preservadas na Biblioteca do IPHAN - BH contêm uma inscrição a lápis no verso, indicando que os originais estariam no Arquivo Publico de Ouro Preto. Infelizmente, em nossa última visita, realizada em maio de 2008 , não nos foi possível localizar o projeto original.

53 APM, AL - PPı/46, Cx.034, 1855/o1/26, Pasta o7.

54 APM, AP - SP, PP1/7, Cx.02, 1862/o7/05, fl. 27.

55 APM, AL - OP, Cx.59-1861-186z, fl. 8. 
A Lei № 686 de 18 de Maio de 1854 abrio um credito illimitado ao Governo para mandar edificar um Theatro nesta Capital: exigindo essa obra grandes despezas, resolvi auxiliar a Sociedade Dramatica, que havia emprehendido o concerto do que ja existe. ${ }^{56}$

Segundo o relatório da comissão fiscal, formada pelos senhores Francisco Eduardo de Paula Aroeira, Valeriano Manso Ribeiro de Carvalho e João Ribeiro Behring, que tinha o objetivo de inspecionar o resultado final das obras de reabilitação do teatro em 1863, as mesmas mantiveram as quatro paredes de alvenaria de pedra e parte do telhado, ao contrário do que afirmam, sem nenhuma fundamentação documental, Evelyn Lima e Nicole Lacroi ${ }^{57}$. Contudo, a fachada principal do teatro foi alterada, introduzindo a empena triangular que vemos atualmente, bem como os elementos decorativos ao estilo neoclássico, que arrematam a frontaria do edifício: a lira central cercada de folhas de acanto, e as duas acroteras laterais (fig. 3$)^{58}$.

Em relação ao óculo tetralobulado presente na atual fachada do teatro, segundo documentos recuperados nos arquivos do Instituto do Patrimônio Histórico e Artístico do Estado de Minas Gerais, é bastante provável que o mesmo tenha sido aberto por volta dos anos de 1880, não fazendo parte, portanto, das inovações introduzidas por Henrique Gerber ${ }^{59}$. Outra inovação no que diz respeito à fachada principal do teatro foi a construção de um "cômodo alpendre", erigido à frente da fachada de alvenaria de pedra preservada da construção setecentista ${ }^{60}$.

A entrada para a plateia continuava a ser feita pela escada central (fig. 4). Contudo, duas escadas adicionais foram abertas junto às paredes laterais do edifício, com a finalidade de facilitar o acesso à sala de espetáculos.

As balaustradas de madeira que serviam de parapeito dos camarotes foram substituídas por balaustradas de ferro, que, segundo o relatório da comissão:

[...] foram executadas todas por José Bento, em sua fábrica do Manso, possuindo algumas empenas, mas como era a primeira

56 APM, Relatório da Assembleia Legislativa Provincial, 1861, p. 22.

57 LIMA, Evelyn; LACROIX Nicole. Théatre et Société dans la région du Minas au Brésil: un public métis pour les salles de spectacle. Canadian Journal of History, XLII, 2007. p. 33 .

58 CASTRO, Celso Falabela de. op. cit., p.75 - 77 .

59 IEPHA-MG, Documentos doados pelo Dr. Aureo Renault, Pasta Casa da Ópera.

6o CASTRO Celso Falabela de. op.cit., p. 75 - 77 . 
obra do gênero, em Minas, deu lugar a que sua colocação ficasse mais elevada, os peitoris eram esmerados e bem talhados pela curva que servia de base aos camarotes. ${ }^{61}$

Em relação aos camarotes, a divisão anterior foi significativamente alterada. Segundo o relatório, antes das obras, o teatro de Ouro Preto contava com camarotes completamente isolados uns dos outros, separados de um corredor por "portinhas corrediças" ${ }^{62}$. Esta disposição é bastante comum nos teatros barrocos de tradição italiana, sendo igualmente a mesma empregada nos teatros públicos de Lisboa, construídos no mesmo período. Após as obras de remodelação, foram mantidos apenas três camarotes isolados dos demais. Além do camarote da Presidência da Província, obviamente ocupando posição central e, todavia preservado, havia dois outros. Sabemos que um deles era destinado à Polícia, e era igualmente bem decorado, contando com tapetes e cadeiras "austríacas"63.

O forro da sala de espetáculos também foi alterado, adquirindo a forma abobadada que vemos nos dias atuais. Segundo o relatório, o antigo teatro possuía um forro plano, assim como os antigos teatros portugueses, entretanto, a nova forma da cobertura da sala em muito contribuía "para a elegância do salão e para retumbo das vozes e dos instrumentos da orquestra" ${ }^{64}$.

Foi confeccionado no Rio de Janeiro um novo pano de boca, onde estava representado o Pico do Itacolomi, emblemática montanha que domina a paisagem natural de Ouro Preto, e novas pinturas decorativas foram realizadas no arco do proscênio, que também tinha sido modificado em relação ao anterior, com suas dimensões originais bastante reduzidas.

Apesar das reformas realizadas, sobretudo na decoração da sala de espetáculos, na fachada principal e na estrutura dos camarotes, é importante mencionar que o edifício mantém algumas importantes características de seu projeto original. A forma da sala de espetáculos em lira, de notável influência italiana, com suas curvas e contracurvas, foi mantida como no edifício setecentista, uma vez que acompanha os alicerces que jamais foram tocados. Salvo pela eventual eliminação da grade de separação entre o espaço reservado para os músicos da orquestra e a plateia, o mesmo segue intacto. Isto é, o teatro não foi alterado para receber as

61 Idem, ibidem, p.75- 77 .

62 Idem, ibidem, p. $75^{-77}$.

63 IEPHA-MG, Documentos doados pelo Dr. Aureo Renault, Pasta Casa da Ópera.

64. CASTRO Celso Falabela de. op. cit., p. 75 - 77 . 
grandes orquestras românticas, como se verifica na grande maioria dos teatros construídos no século XVIII. Outra característica fundamental dos teatros históricos luso-americanos de tradição italiana, preservada em Ouro Preto após as intervenções de 1861/1862, é o formato alongado da sala de espetáculos. Os teatros construídos segundo esta tipologia no mundo português ficaram conhecidos como "teatros-corredores" ${ }^{5}$, e dentre eles, todavia, a Casa da Ópera de Ouro Preto é o único exemplar setecentista preservado. A peculiar forma da sala de espetáculos foi notada por Saint-Hilaire que, em suas anotações de viagem, descreve a sala do teatro mineiro como sendo "pequena e assaz estreita". ${ }^{66}$

A história da Casa da Ópera de Vila Rica, sobretudo no que diz respeito à sua administração, é bastante singular. Construída por um contratador de entradas português, com dinheiro que aparentemente pertencia aos cofres régios, a Casa da Ópera foi um edifício de propriedade particular até 76 anos após o falecimento de seu idealizador, o Coronel Sousa Lisboa. A administração do estabelecimento era feita por empresários que arrendavam o imóvel usando diversos organismos de cobrança: de 1770 a 1778 o aluguel do edifício foi pago a Sousa Lisboa; a partir do falecimento deste, o mesmo passou a ser pago à Real Fazenda Portuguesa, em função da avultada dívida deixada pelo Coronel junto aos cofres régios; após a Independência do Brasil, a cobrança do arrendamento passou a ser feita pela Tesouraria da Fazenda do Império; a partir de 1854, pelo Governo Provincial de Minas Gerais, graças à lei que transferiu o teatro ao poder provincial.

Quando a Casa da Ópera passou a ser um bem público, foi realizada a mais importante intervenção arquitetônica de seus 240 anos de história. Henrique Gerber alterou significativamente a aparência do edifício, sobretudo externa, adaptando a Casa da Ópera ao gosto vigente no Brasil em meados do século XIX. Apesar desta intervenção, o teatrinho ouropretano conserva quase que integralmente sua espacialidade barroca, mesmo contando com a estrutura de sustentação dos camarotes e as balaustradas em ferro fundido, que separam os mesmos do auditório. Possivelmente, o primeiro exemplo de arquitetura do ferro empregado na capital da Província.

Em relação à espacialidade barroca da Casa da Ópera ouropretana, destacamos o espaço destinado aos músicos da orquestra - que jamais fora adaptado para comportar as orquestras românticas -; o

65 CARNEIRO, Luís Soares. Teatros portugueses de raiz italiana. Porto: Faculdade de Arquitetura da Universidade do Porto, 2002. 2v.

66 SAINT-HILAIRE, Auguste. op. cit., v.1, p. 148. 
camarote do Governador, localizado no ponto mais privilegiado do teatro e de onde partia a "perspectiva do príncipe", ou seja, o ponto de onde eram calculados os ângulos de perspectiva dos bastidores que formavam a cenografia dos setecentos; a sala estreita e alongada, que lhe confere status de único exemplar remanescente dos teatros-corredores setecentistas no mundo luso-brasileiro; e ainda, a forma da sala em lira, uma clara influência da arquitetura teatral italiana, conhecida em Lisboa a partir de meados do século XVIII.

A Casa da Ópera de Ouro Preto conserva-se como exemplar único dentro da arquitetura teatral luso-americana setecentista, configurando, também, um espaço de representação privilegiado. Foi palco de eventos da maior importância dentro da história artística de Vila Rica e de Ouro Preto, onde foram representadas obras "segundo o gosto português", traduções de Metastasio e obras de Cláudio Manoel da Costa, além de abrigar obras líricas e teatrais do romantismo, com destaque para a mítica Casta diva, interpretada pela prima-donna Augusta Candiani. Local frequentado por muitos inconfidentes e por outros simpatizantes e detratores do movimento, a Casa da Ópera sofreu com a perda de um de seus maiores colaboradores, o poeta Cláudio Manoel da Costa, e com alguns de seus assíduos espectadores, contudo, sua atividade artística foi mantida de forma ininterrupta. Faz-se ainda, necessário destacar o papel desempenhado pela Casa da Ópera no carnaval de Ouro Preto, primeiro local escolhido pelos organizadores e súditos do carnaval "civilizado", que pretendia acabar com a violência e a confusão do entrudo, organizando grandes bailes de máscaras para a população da então capital mineira. 